\section{A new start}

\section{Adriano Sofo}

School of Agricultural, Forestry, Food and Environmental Sciences, Basilicata University, Potenza, Italy

Dear editors, scientists and readers,

I accepted the role of Editor-in-Chief of the International Journal of Plant Biology with responsibility and enthusiasm. I think that open access journals as ours are the future for scientific publishing and are important for promoting a rapid exchange of research results, experience and ideas among professionals. First of all, I would like to thank the Publications Committee of PAGEPress for my selection. Of course I am aware of the fact that as Editor-in-Chief I will have specific tasks, such as the evaluation and final acceptance of manuscripts, the relationships with the other editors, the efficiency of the whole review process, the choice of the editors more relevant to the topics covered in the Journal. I will try to do it in the best possible way.

I will try to focus my attention on the most exciting and innovative research fields. My desire would be to raise the Journal not only for its scientific impact but also in terms of its spread within the scientific community. For this scope, I will immediately try to advertise the Journal using all available channels, especially at international level. The members of the editorial board, soon available on the website, will have strong experience abroad and consolidated international contacts. I feel confident that the contribution of many authors working in the various fields of plant biology will help us achieve good results. I hope to work with all of you on this exciting project!

Adriano Sofo Editor-in-Chief, International Journal of Plant Biology
Correspondence: Adriano Sofo, School of Agricultural, Forestry, Food and Environmental Sciences, Basilicata University, via dell'Ateneo Lucano 10, 85100 Potenza, Italy.

Tel. +39. 0971.206228 - Fax: +39.0971.204307

E-mail: Adriano.sofo@unibas.it

Received for publication: 28 April 2014.

Accepted for publication: 28 April 2014

This work is licensed under a Creative Commons Attribution NonCommercial 3.0 License (CC BYNC 3.0).

(C) Copyright A. Sofo et al., 2014

Licensee PAGEPress srl, Italy

International Journal of Plant Biology 2014; 5:5468 doi:10.4081/pb.2014.e5468 